\title{
Welcome New Associate Editor Anthony Kim to the World Journal of Surgery
}

\author{
John G. Hunter ${ }^{1}$
}

Published online: 5 February 2018

(C) Société Internationale de Chirurgie 2018

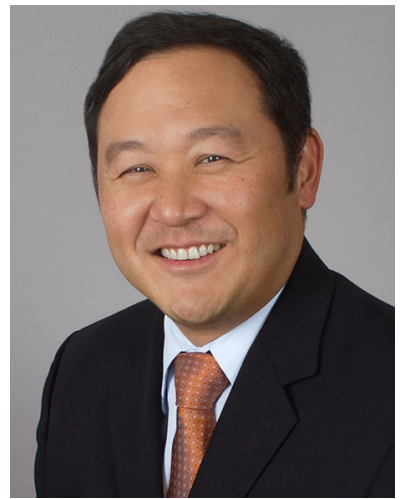

The World Journal of Surgery is thrilled to announce that Anthony W. Kim M.D. has joined our team of world renowned associate editors, focusing on diseases of the thorax and esophagus. Dr. Kim is an academic general thoracic surgeon who holds the Jeffrey P. Smith Endowed Chair of Surgery and is the Chief of the Division of Thoracic Surgery at the Keck School of Medicine of the University of Southern California. His busy clinical practice is dedicated to surgical therapy for the entire range of thoracic diseases and also encompasses utilizing minimally invasive and complex open approaches. Among other clinical and translational areas, his research interests include studying thoracic surgery issues using large datasets. He is well regarded as a faculty mentor to many trainees in medicine and surgery. He also serves on the editorial board for several other major scientific surgical journals. Dr. Kim will provide us guidance and expertise to further the publication of high-impact and high-use manuscripts in the World Journal of Surgery, manuscripts which will transform our understanding of surgical conditions and surgical care.

John G. Hunter

hunterj@ohsu.edu

1 Department of Surgery, School of Medicine, Oregon Health and Science University, Portland, OR, USA 